\title{
Inflammatory damage during both shock wave and intracorporeal laser lithotripsy.
}

Lucero A. Torres-Alarcón1,2, Mario F. Gómez-Núñez¹,2, Mariel Castillo-López, 2, César D. Sánchez-Hernández"1,2, Alberto N. Peón1,3, *

${ }^{1}$ Laboratorio Santiago Ramón y Cajal, Sociedad Española de Beneficencia, Pachuca, Hidalgo; Av. Juárez \#908, Col. La Villita, Pachuca, Hidalgo, México, CP42060.

2 Área Académica de Medicina, Universidad Autónoma del Estado de Hidalgo.

3 Escuela Superior de Apan, Universidad Autónoma del Estado de Hidalgo. Carretera Apan-Calpulalpan s/n, Colonia 43920 Chimalpa Tlalayote, Hgo, México.

\section{Abstract}

Nephrolithiasis is a condition that in most cases requires the use of either shock wave lithotripsy or intracorporeal laser lithotripsy. Although both treatments are considered to be non-invasive, or minimally invasive, respectively, some reports have shown that they produce mechanical and/or thermal damage to the renal tissues, and at least the shock wave lithotripsy is also involved in the induction of ischemia-reperfusion at the kidneys. As such, a predominantly innate immune response arises where monocytes/macrophages, natural killer cells and neutrophils are involved in the amplification of kidney damage, whereas M2 macrophages and T-regulatory cells are involved in the mitigation of such inflammation-dependent damage. In this way, the modulation of inflammation during the therapeutic process may be an adequate target to limit lithotripsyinduced kidney injury. However, much specific research is needed in order to propose a pharmacological strategy for this.

\section{Highlights}

The safety of a widely-used therapy is discussed.

Shock wave lithotripsy produces mechanical damage.

Intracorporeal laser lithotripsy produces thermal damage.

\section{Keywords}

Lithothripsy

Shock wave

Laser

*Correspondence should be addressed to: investigacion@benepachuca.com 
SÖC̊IIÉÉÁAD

ESPAÑOLA BENEFICENCIAAC

P A

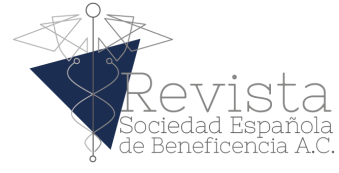

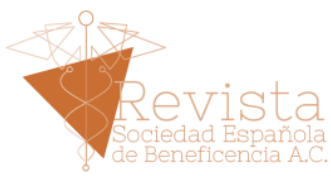
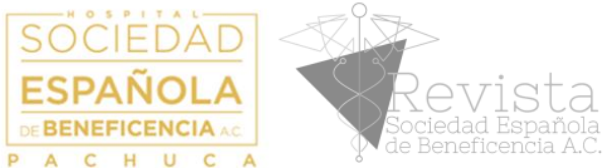

\section{Introduction}

Acute kidney injury (AKI) is a syndrome characterized by a rapid (hours to days) decrease in renal excretory function, which causes the accumulation of many nitrogen metabolism-derived products, among of which creatinine and urea stand out because they are clinically measured. Other traits that strongly associate with AKI are a decreased urine output, accumulation of metabolic acids, and increased potassium and phosphate concentrations ${ }^{1}$; nonetheless, the extent of such variations has a wide margin. Such principles have led the Acute Dialysis Quality Initiative to propose a definition/classification for AKI that is called RIFLE, an acronym for risk, injury, failure, loss of function and end-stage criteria ${ }^{2}$, where the elevation of serum creatinine concentration and the decrease in glomerular filtration rate (GFR) are measured to determine if a patient is at risk of AKI, has an episode of AKI, and the extent of damage induced by it. AKI is typically thought to be produced as a consequence to nephrotoxicity, ischemia, mechanical stress that leads to tissue injury, sepsis and acute decompensation of heart failure ${ }^{1,3-5}$. And interestingly, all of these conditions involve some degree of local kidney inflammation, as thoroughly discussed in ${ }^{4,6}$.

Furthermore, chronic kidney disease (CKD) is defined as a massive loss of GFR and/or the presence of kidney damage, measured as pathological changes documented on imaging or biopsy and proteinuria ${ }^{2}$. By itself, CKD represents a serious condition that may impact negatively on the function of many organs, but it may also progress to end-stage renal disease (ESRD). CKD is thought to be a consequence of prolonged and severe AKI, especially when it goes without treatment ${ }^{8}$, which is frequent as there is a vast unawareness among patients with CKD markers about their kidneys' health 9,10. Moreover, health practitioners may also be unaware of some of the etiological entities that may induce a certain degree of AKI that could progress to CKD, as both conditions are vastly understudied and thus, not entirely understood. This phenomenon, in part, is due to the lack of animal models that are truly representative of the human pathology, but also because its study in humans depends upon biopsies taken from cadavers, that already have suffered a death-derived ischemia ${ }^{4,6}$.

On the other hand, nephrolithiasis (kidney stones) is one of the most common nephrological pathologies ${ }^{11}$, and it has a high worldwide prevalence, with rates ranging from 7 to 13\% in North America, 5-9\% in Europe, and 1-5\% in A.sia ${ }^{12}$. It is a complex disease where many epigenetic/environmental triggers such as climate, diet, fluid intake and occupation have been described, but also genetics, gender, and age appear to play a role in the disease ${ }^{13}$. Kidney stones are already perceived as a highly unpleasant nuisance by patients and doctors alike, but the general concern regarding its long term consequences has recently increased ${ }^{14-}$ ${ }^{16}$, as it has been pinpointed as a cause of AKI, CKD and ESRD ${ }^{17-19}$, both of which could be prevented by means of appropriate treatment and follow up ${ }^{20}$. 
SÖC̊IIÉÉÁAD

ESPAÑOLA BENEFICENCIAAC

P A $\quad$ C

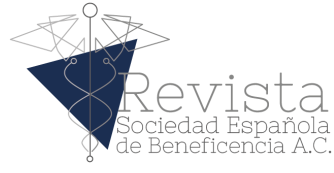

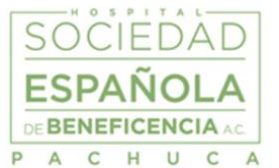

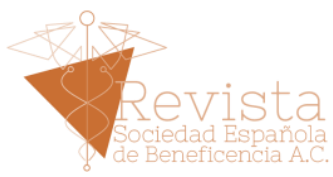

SOCIEDAD

ESPAÑOLA

BENEFICENCIA

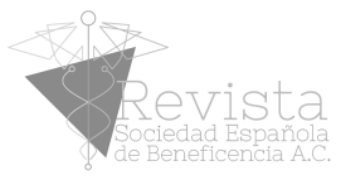

One of the most common treatments for such a condition is lithotripsy, where there are two main approaches: the shock wave lithotripsy (SWL), which comminutes stones by acoustic waves, and the intracorporeal laser lithotripsy (ILL), that destroys stones by light waves. Strikingly, SWL has been shown, both in animal models ${ }^{21-23}$ and human studies ${ }^{24-27}$ to produce renal inflammation and thus AKI. Additionally, recent research in animal models have shown that AKI occurs also by laser lithotripsy 28,29. Nonetheless, the modifications to the conventional SWL protocol that have to be made in order to control inflammation do not allow for a full spectrum of stone comminution, so that standard SWL has been slowly but steadily been replaced by ILL, which has the potential to induce thermal damage to the kidneys, and thus induce a different kind of inflammation ${ }^{28}$, although research regarding this topic has been neglected.

In such an understanding, we think that it may be important to review the current knowledge in the field of lithotripsy with aims to understand the inflammatory process behind such a therapeutic approach, as it may serve the purpose of enhancing awareness about its potential to produce AKI and CKD, but it may also be of use to pinpoint the need to investigate new combinatorial therapeutic approaches that may limit inflammatory damage by this necessary, and currently irreplaceable, therapy.

\section{Urolithiasis: types and clinical management}

Urinary tract stones exhibit great variations in their physical, chemical, anatomical and pathogenical conditions, thus requiring different therapeutic approaches 30,31. Urinary stones can be classified according to the following aspects: chemical composition, size, and location; although the etiology of stone formation must also be taken into account ${ }^{32}$.

\subsection{STONE LOCATION}

Urinary stones are primarily classified by their localization within the urinary tract. When they are located in the kidney, the pathology is called nephrolithiasis, in the ureter is called ureterolithiasis or in the bladder, cystolithiasis. Within the kidneys the stones can be located in the renal papillae, upper calyx, middle calyx or lower calyx, as well an in the renal pelvis ${ }^{33}$. They form over long periods of time, by a slow process of mineral aggregation, and can stay adhered in such locations, or suddenly detach to travel through the ureters and out of the body with the urine. But any kidney stone is also prone to get stuck in the urinary tract and block urine deposition. It is thought that a patient might remain unaware of kidney stones until stone detachment and further movement within the urinary tract, which causes tissue damage and pain.

\subsection{STONE SIZE}


SOHCIÉÉÁÁ

ESPAÑOLA DEBENEFICENCIAAC

P $A$ A $C$ C H U C C A

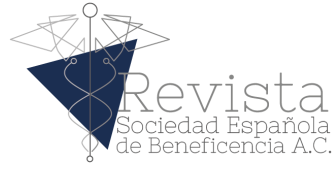

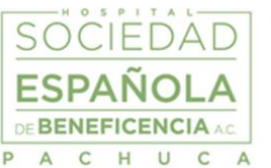

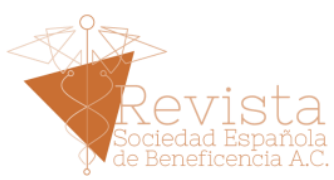

SOCIEDAD

ESPAÑOLA

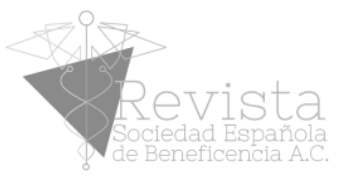

Kidney stones can be as small as a grain of sand or as large as a pearl, ranging from $1 \mathrm{~mm}$ to $\geq 20 \mathrm{~mm}^{33}$. Stone size is usually given in one or two dimensions, and stratified into those measuring up to 5, 5-10, 10-20, and $>20 \mathrm{~mm}$ in their largest diameter ${ }^{34}$. Small stones are treated with a conservative management (hydration, analgesics, prophylactic antibiotics, and $\boldsymbol{\alpha}$-blockers to favor stone expulsion), but stones above $5 \mathrm{~mm}$ in size are less likely to pass spontaneously and patients should be remitted to other treatment options, such as percutaneous nephrolithotomy, or most commonly, some kind of lithotripsy 35,36.

\subsection{STONES CLASSIFIED BY ETIOLOGY}

The stones are classified by etiology in non-infection related, infection related and genetic related causes.

\subsubsection{NON-INFECTION RELATED STONES}

This group has an intimate relationship with the gradual accumulation and concretion of the minerals in the urine until a stone is formed, within the main types of such calculi are those made of calcium oxalate, calcium phosphate and uric acid. This group has no direct relationship with infections. If these type of stones are not completely removed, they will keep growing by the addition of new crystals ${ }^{37,38}$.

\subsubsection{INFECTION-RELATED STONES}

This type of stones are formed when a persistent pyelonephritis exists, in which urease-producing bacteria like Proteus mirabilis, Klebsiella pneumonia, Pseudomonas aeruginosa, and Enterobacter spp. that enzymatically transform urea to ammonia, which has a tendency to aggregate within the kidneys to form stones 39.

\subsubsection{GENETIC-RELATED STONES}

Cystine stones are very rare, as they are the product of a defective transport of such amino acid dimer in the renal tubules that occur due to mutations in the SLC3A1 and SLC7A9 genes, which code for the subunits of the rBAT/D amino acid transporter. As such, cystinuria causes cystine to accumulate in the kidneys and form a stone ${ }^{40}$.

\subsection{STONE COMPOSITION}

One of the most important classification of stones is made according to their chemical composition, so that they are named after its predominant mineral contents. The most common stones, in order, are calcium-based stones, struvite, uric acid and cysteine ${ }^{41}$. Chemical composition is strongly linked with size, shape and density, so that it is a primal determining factor on the clinical management of the case.

\subsubsection{Calcium StOneS}


SÖC̊IIÉÉÁAD

ESPAÑOLA BENEFICENCIAAC

P $A$ A $C$ C

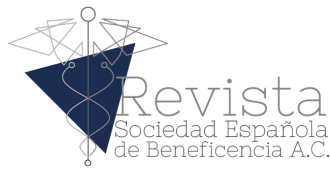

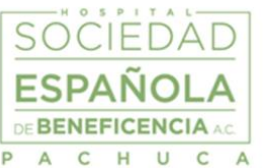

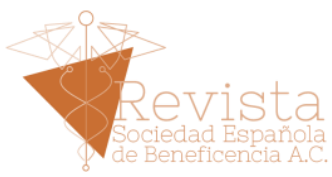

With a prevalence of $75-80 \%$ these are the most common type of kidney stones 31. Calcium calculi are usually conjugated with oxalate (a natural chemical found in most foods), phosphate or both (4-5). Calcium oxalate ( $\mathrm{CaOx}$ ) stones account for $50 \%$ of calcium stones, but calcium can also be conjugated with phosphate (CaP, termed as apatite) (5\%), or a mixture of both (45\%) ${ }^{42}$. CaOx is called brushite when it is hydrated, or less frequently hydroxyapatite, when it is hydroxylated ${ }^{43}$. Many factors contribute to CaOx stone formation such as hypercalciuria, hypercystinuria, hyperuricosuria, hypomagnesuria, hypocitraturia, and hyperoxaluria 44. Also a urine pH of 5.0 to 6.5 promotes CaOx stone formation, but CaP stones occur when $\mathrm{pH}$ is greater than $7.5^{31}$.

\subsubsection{STRUVITE STONES}

The struvite stones, also called triple phosphate stones, are composed by magnesium, ammonium and phosphate, and they have a prevalence of $15 \%$. ${ }^{4}$. These stone's etiology is associated with different types of urinary tract infections, in which bacteria make ammonia through urea cleavage. The pathogens that most commonly associate with this type of lithiasis include Proteus mirabilis, Klebsiella pneumonia, Pseudomonas aeruginosa, and Enterobacter spp ${ }^{30}$. Struvite stone formation is dependent upon bacterial urease activity, which is necessary to cleave urea to ammonia and $\mathrm{CO}_{2}$, making urine more alkaline, so phosphate precipitates onto the insoluble ammonium products, aggregating to form large staghorn-like stones ${ }^{45}$, which is mostly impossible to extract without a previous lithotripsy treatment.

\subsubsection{URIC ACID STONES}

These type of stones have a prevalence of 6-10\% ${ }^{31}$, and they are often formed when the urine is too acidic. Uric acid can form stones by itself or in combination with calcium. These are characteristically seen in patients with hyperuricemia induced by diets that are high in purines, or in animal proteins, such as meat and fish, which results in hyperuricosuria and low urinary $\mathrm{pH}$ (pH < 5.05), both characteristics that exacerbate uric acid crystal aggregation, and thus stone formation ${ }^{46}$.

\subsubsection{CYSTINE STONES}

These are made of cystine, a chemical that the body makes naturally, and are very rare as they have a 1\% prevalence. Cystine stones tend to happen in patients who have a defective cystine transporter in the proximal tubule, leading to a decreased reabsorption of such aminoacid dimer ${ }^{31,47}$.

As made obvious in this section, nephrolithiasis is not a single disease, but a group of diseases. This compels nephrologists and urologists to adapt their therapeutic strategies in order to provide the best solution for each case.

After emergency situations have been ruled out and adequate analgesia has been achieved, the next step is to formulate a strategy for managing the stone. There 
SÖC̊IIÉÉÁAD

ESPAÑOLA BENEFICENCIAAC

P $A$ A $C$ C

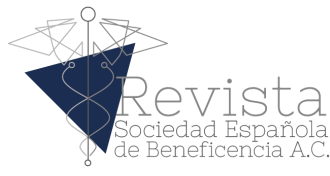

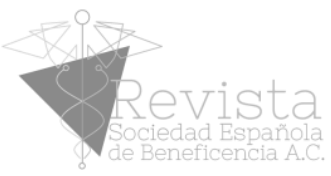

are three major prognostic factors that aid in such decisions: stone size, density and location.

\subsubsection{THERAPEUTIC APPROACH}

Stones with less than $5 \mathrm{~mm}$ have $>90 \%$ of opportunities to be eliminated through urination. In fact, for stones less than $4 \mathrm{~mm}$ in size generally pass within one to two weeks ${ }^{48}$, while $80 \%$ percent of this patients require no intervention beyond analgesia ${ }^{49}$, or even $\beta$-blockers to help in smooth muscle relaxation and stone expulsion. On the other hand, uric acid calculi can sometimes be dissolved by prolonged (4 to 6 months) alkalization of the urine by potassium citrate oral intake 50, however this treatment is not effective for other types of stones. Moreover, for stones with a diameter $\geq 2 \mathrm{~cm}$, an irregular shape ${ }^{51}$, or that could not be comminuted by SWL 52, the preferred choice is the percutaneous nephrolithotomy which consists on opening a small incision on the infracostal fraction of the back to insert a nephroscope, which is a small catheter with a camera and tools to remove the stones ${ }^{53}$.

If a stone is more than $5 \mathrm{~mm}$ in its biggest diameter, but does not reach $2 \mathrm{~cm}$ in size, and it has a chemical composition different from uric acid, then the preferred therapy is lithotripsy, which will be discussed in the section below.

Either way, pain management is usually achieved by the use of opioids such as morphine and fentanyl or non steroideal antinflammatory drugs like Ketorolac. Also, persistent vomiting due to nausea and excruciating pain, if it happens, can be treated with an antihemetic ${ }^{54,55}$. However, no other drugs have been tried during the process, and to no other purpose than pain and vomiting control medication has been employed.

As such, it is evident that the divergences between the different types of stones compel the clinical practitioners to treat each type of nephrolithiasis differently, but it is also evident that in most cases some type of lithotripsy can be considered the treatment of choice (3). Accordingly, it is important to discuss the pathophysiological changes that arise as a consequence of such treatment, to include the vastly neglected inflammatory damage that derives from such procedure.

\section{Lithotripsy: different types of therapy and different types of damage}

As a consequence to the aforementioned diversity in renal calculi, lithotripsy (which is considered as the main therapeutic strategy to break them) has been diversified into, mainly, two types: the extracorporeal SWL (ESWL), which uses particular kinds of high energy acoustic waves to break the stones, and the flexible ureteroscopy and laser lithotripsy (FURSL) or ILL, which uses infrared-spectrum light to comminute the calculi.

\subsection{SHOCK WAVE LITHOTRIPSY: USES AND RISKS}




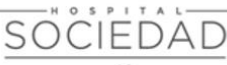

ESPAÑOLA BENEFICENCIA $A C$

$P$ A C

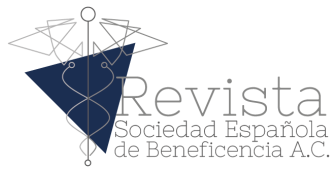

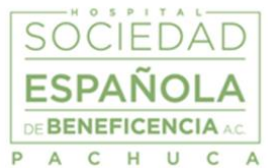

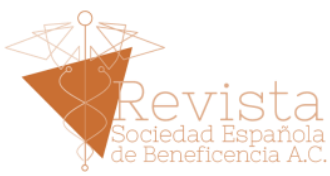

Shock waves (SW) are defined as a sequence of single sonic pulses with a high peak pressure (in the range of 10 to almost $100 \mathrm{MPa})$ and a fast rise pressure $(\approx 10$ ns), with a duration of around 1 second. An advantage of SW is that they can be focused at specific regions from the outside of the body, so that they can be used extracorporeally ${ }^{56}$. In this way, ESWL is a non-invasive method that is able to comminute calculi through sonic vibrations ${ }^{57}$.

Although ESWL has been the standard treatment for most nephrolithiasis cases since its introduction in the 80's, there has been much debate regarding the types of physical properties the SW must have to properly comminute stones, and avoid complications at the same time. Moreover, although ESWL is considered as a non-invasive method, it has been associated with side effects and complications, where the main mechanisms for damage induction are mechanical injury to parenchymal cell membranes ${ }^{58}$ and renal vascular damage, which relates to the induction of ischemia, which produces further necrosis of the kidney's parenchyma ${ }^{59}$. A clinical sign of kidney trauma is haematuria, and the collection of perirenal, subcapsular, or intrarenal fluid ${ }^{60}$, and enhanced levels of serum creatinine ${ }^{61}$. Such vascular injury is associated with a transient decrease in renal blood flow and glomerular filtration rate in the treated kidney, as well as some acute changes including enlargement of the treated kidney, loss of corticomedullary demarcation, and low-intensity perinephric fat changes in 63\% to 85\% of the patients ${ }^{62}$. Some other side effects that ESWL had are pain in the costovertebral angle, petechiae at the entry and exit point of the shock waves, microscopic or gross hematuria, fever, nausea with vomiting and acute urinary retention ${ }^{63}$.

In such debate, many types of SW have been explored, in order to find the best results at stone destruction, while producing the least amount of AKI. For instance, it has been described that high SW energy levels are able to destroy almost every other type of calculi, but studies show that better results arise when a low energy (13-14 kV) is used at first but it gradually increases in intensity ${ }^{64}$. In contrast, some researchers have shown that lower frequencies $(60 \mathrm{~Hz})$ perform better than higher $(120 \mathrm{~Hz}) 65$ at stone comminution. Such data is supported by a clinical study performed by Chacko et al. ${ }^{66}$ which included 349 patients with renal and proximal ureteric stones of $1-2 \mathrm{~cm}$ and showed that $70-80$ shocks/minute had better results in comparison with 120 shocks/minute.

On the other hand, many studies about kidney injury have shown that the extent of damage is related to the number of shocks, level of energy delivered and the focal size of the shock wave, as thoroughly reviewed in ${ }^{67}$. As such, treatments using 2000-3000 SW and 16-24 kV have been described to produce the most damage to both the renal parenchyma and the renal blood vessels, whereas treatments with 100-500 SW and a maximum of $12 \mathrm{kV}$ have been described to produce the least amount of it 21,23,68. In contrast, Mustafa and colleagues showed that the treatment with an electrohydraulic lithotripter that started with an energy level of $12 \mathrm{kV}$ and gradually increased to $19 \mathrm{kV}$ produced less damage than an electromagnetic lithotripter that used an energy level in the range of 1 to $7 \mathrm{kV}$, while both lithotripters used a rate of SW delivery of $60 \mathrm{SW} / \mathrm{min}$. AKI was demonstrated by three urine cytological examinations, one made pre-SWL treatment, another im- 
SÖC̊IIÉÉÁAD

ESPAÑOLA BENEFICENCIA $A C$

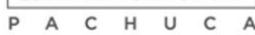
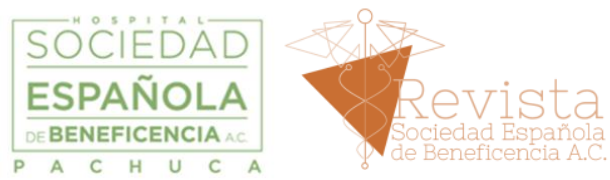

mediately post-SWL and the last one 10 days after SWL, where they found a significant increase in the number of red blood cells and epithelial cells of the postSWL cytological examination from the electromagnetic lithotripsy-treated group 58.

Taken together these data show that despite its no-invasiveness, SWL is able to induce AKI. Although some research has been done with aims to optimize stone comminution and reduce SWL-induced damage, there is not an entirely clear panorama about the best way to perform such therapy. One option has been to adapt the kind of lithotripsy to the stone's characteristics, for example, as higher density calculi require a greater level of SW-energy, which induces an enhanced damage, this type of stones is preferably treated with ILL ${ }^{69}$.

\subsection{INTRACORPOREAL LASER LITHOTRIPSY: USES AND RISKS}

Despite the success that ESWL has had in the management of urolithiasis, ILL has been proposed as a more modern and safer alternative. In this way, it is also important to review the current data about its safety, especially as some recent data indicates that ILL is not entirely harmless.

In ILL, laser activation causes the release of energy from the fiber-tip, which creates a vapor channel, allowing direct absorbance of radiation by the stone, which leads to a photothermal reaction that causes chemical decomposition of the calculus. All this effects depend on the total power (Watts) delivered to the stone, and this power is the product of the pulse energy and frequency ${ }^{70}$. Next-generation holmium lasers can be adjusted in pulse energy (Joules), frequency (Hertz) and pulse duration (microseconds), because in that way stone fragmentation can be enhanced, while calculi retropulsion can be avoided, and laser fiber-tip degradation can be delayed ${ }^{71}$. The retropulsion is a shortcoming of ILL that occurs while the procedure is being carried out, in which the fluid surrounding the calculi evaporates and expands, creating a vapor bubble, and its collapse leads the stone to move away from the laser tip ${ }^{72}$, which decreases fragmentation efficiency may produce mechanical damage as the moving stone scratches the internals of the kidney.

Although the optical energy emitted from the laser fiber-tip or pulse energy (PE) can vary from 0.2 to $6.0 \mathrm{~J}$, the users commonly occupy the range between $0.2-2$ J. The final choice of PE-intensity is dependent upon the hardness and density of the calculi, i.e. higher PE such as $1.0 \mathrm{~J}$ is ideal for comminuting harder and denser stones (such as those made of calcium), but this method has to be followed by active basket retrieval, because it produces bigger stone fragments, in a process called "pop-dusting", and such fragments may not be eliminated spontaneously, allowing for calculi re-concretion. On the other hand, when a calculi is softer and less dense, a "dusting" technique to create very small sub-millimetric fragments that are candidate to spontaneous passage is used by turning the lithotripter to a lower PE, such as $0.2 \mathrm{~J} 72,73$.

Moreover, frequency is the number of optical pulses emitted in one second, a range of 15 to $80 \mathrm{~Hz}$ is commonly the first choice. On the other hand, the duration 
SÖC̊IIÉÉÁAD

ESPAÑOLA BENEFICENCIA $A C$

P $A$ A $C$ C

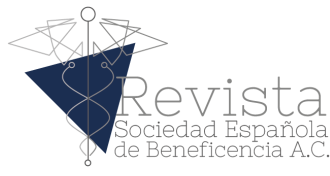

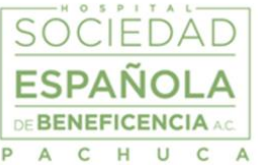

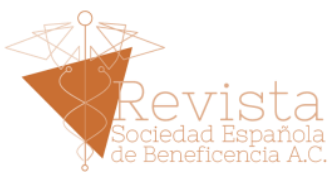

of time in which a single optical pulse is emitted is called pulse duration, and it is divided into two types: short pulses that varies from 150 to 350 us, and long pulses which can last up to 1,200 us. The main advantage of using long pulse is that this decreases retropulsion distances. In this way, shorter pulses are preferred in order to avoid stone-retropulsion mediated mechanical damage, while a more intense PE is the optimal choice when the stones are harder. Because of its higher effectivity at comminuting harder stones, the offered possibility of adapting its parameters to act better against certain types of stones and the idea that it is safer than SWL, ILL has become the treatment of choice in the recent years ${ }^{74}$. However, recent data indicates that no differences between SWL and ILL exist regarding damage production ${ }^{28}$. In such an understanding, we think that it may be important to analyze this topic.

Laser lithotripsy induces stone fragmentation through the direct absorption of energy by the calculus. In this way, laser energy is transmitted to the stone surface by means of radiating energy transfer, and an accompanying vapor bubble that is created at the fiber tip during activation of the laser. Additionally, the collapse of the vapor bubble may also produce a weak acoustic effect ${ }^{75}$. Lower pulse energy settings result in smaller stone fragments and less retropulsion. As the pulse energy is increased, fragment size increases, as does the degree of retropulsion ${ }^{76}$. But, additionally, recent in vitro studies where heat generation was measured in relation to differences in laser pulse length and pulse type showed that long pulses, and greater power produced significantly higher maximum temperatures ${ }^{7,78}$. Furthermore, a recent study by Aldoukhi, et al. ${ }^{29}$ showed that in a high power setting, the increase in the temperature of the calyx fluid is enough to induce a considerable heath-derived damage to the kidneys, while hematomas were also produced. The effects of increased irrigation on temperature were also investigated, finding that an in situ irrigation rate of $40 \mathrm{ml} / \mathrm{min}$ was enough to mitigate such thermal damage. Despite this, the kidneys face a great internal pressure under the aforementioned irrigation conditions, which may still cause enough vascular damage to develop renal hematomas ${ }^{79-81}$.

These data taken together make apparent that both types of lithotripsy are linked to some degree of AKI. Although these arguments do not pretend to discard such a good and non-invasive therapeutic option, we think that more research is needed in order to develop strategies that limit the lithotripsy-associated damage. As such, the first step that becomes necessary is to understand the inflammatory responses that are triggered by lithotripsy, in order to pinpoint the pathophysiological mechanisms that may be blocked to limit damage.

\section{Immunopathology in lithotripsy}

AKI, has been described as a rapid decrease in kidney function as measured by increases in serum creatinine, a process that can manifest from a few hours to less than 3 months after damage induction ${ }^{82}$. AKI involves hemodynamic alterations, and endothelial/epithelial cell injury, which causes inflammation to further 
SÖC̊IIÉÉÁAD

ESPAÑOLA BENEFICENCIAAC

P A $\quad$ C

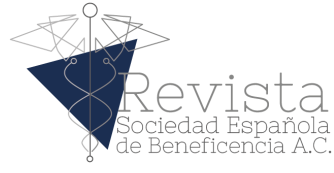

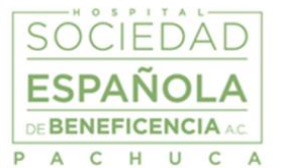

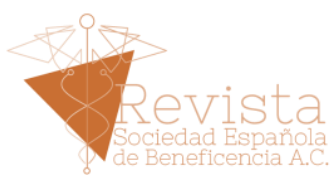

potentiate damage. What strikes as interesting is the fact that during lithotripsy, tissue damage occurs mainly in two ways: i) due to direct mechanical injury to the renal parenchyma, and ii) due to ischemia ${ }^{83}$. In SWL mechanical injury is mainly caused by the increased movement and vibration of the stones, whereas in ILL it appears to be caused by a thermal increase. Either way, the innate and adaptive immune responses induced during lithotripsy have been linked to enhanced AKI, which could derive in CKD. Nonetheless, we lack data regarding the long term effects of both types of lithotripsy.

4.1 Shock WAVE Lithotripsy AND MECHANicAl-DAMAGE INDUCED INFLAMMATION

As SWL is an acoustic technique that comminutes stones by causing vibrations, it has been described that these move within the kidney, retrotracting away from the focal point. In this way, it has been recommended to point at the renal calyx, or to use additional devices to contain stone movement 84,85 . Nonetheless, such migration may produce mechanical damage to the internal zone of the kidneys. To our knowledge, there are no data regarding the possibility of shock waves directly damaging the renal tissue, but such pathophysiological mechanism should not be ruled out as tissue damage by lithotripsy has been detected not only in the surrounding's of the calculi, but also deep into the renal medulla and cortex. Either way, acute tissue damage has been detected to induce a local innate immune response, which elevates the expression of tissue damage, oxidative stress and inflammation markers.

For instance, recent research by Chung et al ${ }^{21}$ shows that rat kidney tissue had enhanced levels of inflammatory markers like intracellular adhesion molecule-1 (ICAM-1), heat shock protein-70 (HSP-70), macrophage chemotactic protein (MCP-1) and tumor necrosis factor $-\alpha(\mathrm{TNF}-\alpha)$, when treated with SWL. The levels of such markers increased when the rats were treated for more than one time, suggesting that repeated therapies may enhance the inflammatory response to SWL. Moreover, it has been described that SWL-treated pigs have an enhanced TNF- $\alpha$ and IL-6 excretion in urine ${ }^{22}$ as well as increased expression of oxidative stress-derived markers ${ }^{86}$. Importantly, although the treatment with low power SWs was shown to completely dampen TNF- $\alpha$ urination, tissue levels of IL-6 and hemoxigenase-1 (HO-1) (a marker of oxidative stress) were not entirely abrogated 68. Interestingly, nitric oxide (NO) production has been linked as the main immunopathogenic mechanism of damage induction by SWL, as the inhibition of $\mathrm{NF}-\mathrm{kB}$ (and therefore NO) by the pretreatment with curcumin has shown a significant reduction in glomerular and tubular damage ${ }^{87}$ (Fig. 1). 
SÖC̊IIÉÉÁtD

ESPAÑOLA BENEFICENCIA $A C$

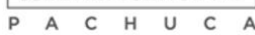

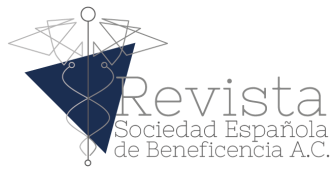

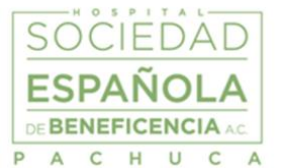

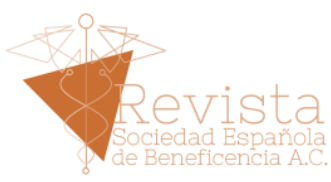

Such observations on animal models are paralleled by clinical studies (reviewed in ${ }^{24}$ ) where a correlation between SWL and the elevation of inflammatory cytokines like IL-6 88,89 and IL-1 $\alpha^{88}$ has been detected. We lack data to confirm the participation of such inflammatory markers in the induction of further inflammation-derived damage in human patients, but using the data available from animal models it can be inferred that the innate immune response and the production of high levels of $\mathrm{NO}$ may be among the most important factors associated to the process (Fig. 1).

\subsection{SHOCK WAVE LITHOTRIPSY AND ISCHEMIA-REPERFUSiON MEDIATED INFLAMMATION}

Both the endothelium and small arterioles have been documented to suffer damage by SWL application. As a consequence of the local vascular compromise increased levels of the vasoconstrictors endothelin-1, angiotensin II, thromboxane A2, leukotrienes C4 and D4 are produced ${ }^{90}$, as well as many necrotic debris. This impacts producing a considerable reduction in blood flow to the outer medulla, thus affecting kidney perfusion ${ }^{91}$. Such process is thought to enhance cell necrosis by hypoxia induction, thus amplifying tissue damage, and potentiating inflammation. As a consequence, an increased expression of cell adhesion molecules such as ICAM-1 92 and of proinflammatory cytokines TNF- $\alpha$, IL-1 $\beta$, IL-6, IL12, IL-15, IL-18, IL-32 have been detected ${ }^{93}$. Such cytokines have diverse effects on the activation of both the innate and adaptive immune responses, which include a rise in the expression of Toll-like receptors (TLR) 2 and $4{ }^{83}$, as well as MHCII ${ }^{94}$, and the costimulatory molecules CD28, B7-1 and B7-2 95 on the surface of the remaining tubule cells in order to enhance a Th1 adaptive immune response 96 (Fig. 1).

Necrosis-derived damage associated molecular patterns (DAMPs) like extracellular ATP and chromatin, along with ICAM-1 expression, platelet activation and IL-1 $\beta$ production seem to be able to recruit and activate neutrophils, which potentiate tubule necrosis by reactive oxygen species (ROS) and myeloperoxidase deposition, as well as neutrophil extracellular traps (NETs) formation ${ }^{97}$. Neutrophils have been clearly linked with renal ischemia reperfusion-derived damage, as reduced serum creatinine, urea nitrogen and renal tissue damage have been detected in animal models where neutrophil recruitment is abrogated through the use of antinflamatory agents, such as celecoxib ${ }^{98}$ and rutaecarpine ${ }^{99}$. Additionally, a pharmacologically-induced increase in kidney blood flow with both pentoxifylline ${ }^{98}$ or clopidogrel ${ }^{100}$ was demonstrated to block neutrophil recruitment, and thus damage. Moreover, when the recruitment of both neutrophils and NK-cells was blocked by osteopontin neutralizing antibodies, reduced levels of blood urea nitrogen and creatinine were detected, suggesting that also NK cells have an important role in the inflammatory pathophysiology of such treatment 101 (Fig.1). 


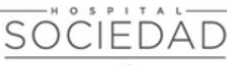

ESPAÑOLA BENEFICENCIA $A C$

$P$ A C H U C A

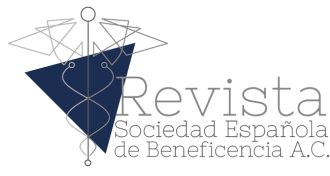

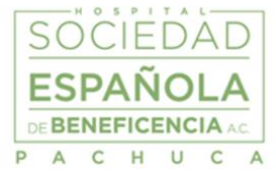

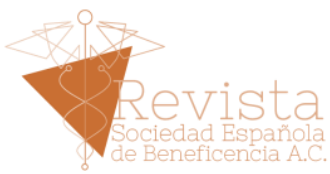

Moreover, macrophage numbers increase in the mouse kidney 1 hour after ischemia-reperfusion, peaking at 24 hours and persisting for 7 days 102 to potentiate damage and inflammation, as they produce ROS, IL-1 $\beta$ and TNF- $\alpha^{83}$. The inhibition of its migration using periodate-oxidized ATP, an antagonist of the P2X7 receptor is able to considerably dampen macrophage-mediated damage ${ }^{103 .}$ Moreover, Masola and colleagues recently showed 104 a crosstalk between hypoxic tubular cells and macrophages, where the former are able to induce the latter's recruitment and activation into the proinflammatory M1 phenotype, leading them to produce high nitric oxide synthase (iNOS) levels, IL-1 $\beta$ and TNF- $\alpha$ through the production of heparanase, a hypoxic-related stress protein. When the expression of heparanase was inhibited by a small hairpin RNA, ischemic damage was very limited, suggesting a potentially important role for M1 macrophages and their NO production in the induction of renal damage after reperfusion. Interestingly, a rat model of renal ischemia reperfusion injury showed that the treatment with atorvastatin was able to induce the transition from an inflammatory M1 to an anti-inflammatory M2-type of macrophages, reducing the levels of several AKI markers, TNF- $\alpha$ and IFN- $\boldsymbol{\gamma}^{105}$.

In this way, both macrophage and neutrophil-derived damage appear to be dependent upon $\mathrm{NO}$ production, in such a way that the general inhibition of oxidative stress has been shown to be protective in the setting of renal ischemiareperfusion ${ }^{106}$. Nonetheless, the role of effector T-cell responses is rather unclear. First, both memory and effector T-cytotoxic and T-helper cells, as well as B-cells have been described to rapidly recruit after ischemia reperfusion, remaining in the reperfused kidney for at least 6-8 weeks. Moreover, the depletion of the whole $\mathrm{CD}^{+}$and $\mathrm{CD} 8^{+} \mathrm{T}$ cell fraction before, but not after, ischemia-reperfusion significantly reduced damage to the renal medulla and production of IFN$\mathbf{\gamma}^{107}$, whereas Th17-differentiation of CD4 $4^{+}$T-cells trough STAT3 signaling 108 and IL-17 production have been linked to the worsening of renal pathology ${ }^{109}$. In this way, the role of adaptive immunity in the potentiation of renal damage seems somewhat clear. Nonetheless, excellent recent investigations about the role of CD4+ $\mathrm{T}$-cells in such pathology pose an interesting contradiction to the role for adaptive immunity in the whole phenomenon (Fig. 1).

For instance, Xue et al. ${ }^{110}$ showed that IкB $\alpha \Delta \mathrm{N}$-Tg mice, which have a T-cell specific genetic ablation of NF-kB, have reduced serum creatinine, BUN, and pathologic damage, with a significant downmodulation of both T-cell and neutrophil recruitment after kidney ischemia reperfusion. But, on stark contrast, Guo and colleagues ${ }^{111}$ showed that the T-cell specific knockout of the NF- $\mathbf{k B}$ activating kinases IKK2 or NEMO were related to increased AKI, correlating with enhanced levels of Th17 cells, which presumably activate neutrophils. On the other hand, Yano et al. ${ }^{112}$ showed that IL-18R $\alpha$-deficient mice had increased levels of BUN, tubular damage, and bigger CD $4^{+} \mathrm{T}$ cell, neutrophil, and macrophage infiltration levels, while having an increased mRNA expression of proinflammatory cytokines like IL-1 $\beta$, IL-12p40, and IL-18, as well as chemokines like MCP1. These effects were linked to the downmodulation of the apoptosis-promoting FasL protein, suggesting that the Th1 response occurs as a strategy to limit necrosis by promoting apoptosis. Moreover, IL-17-treated mesenchymal stem cells are able to 
reduce tubular necrosis, serum creatinine and BUN, also recruiting an enhanced population of Treg cells ${ }^{113}$ (Fig. 1).

As such, we think that the role for both the Th1, and the Th17 cells in renal ischemia reperfusion is not clear, and the only consensus regarding T-cell activity during such pathology is that Treg cells are able to modulate the intensity of the whole pathology, as the depletion of $\mathrm{CD} 4^{+} \mathrm{CD} 25^{\text {high }} \mathrm{CD} 127^{\text {low }} \mathrm{T}$-regulatory cells by means of $\alpha$ CD25 antibody have demonstrated that such a cellular fraction is involved in damage regulation and improved renal function preservation ${ }^{114,115}$ (Fig. 1).

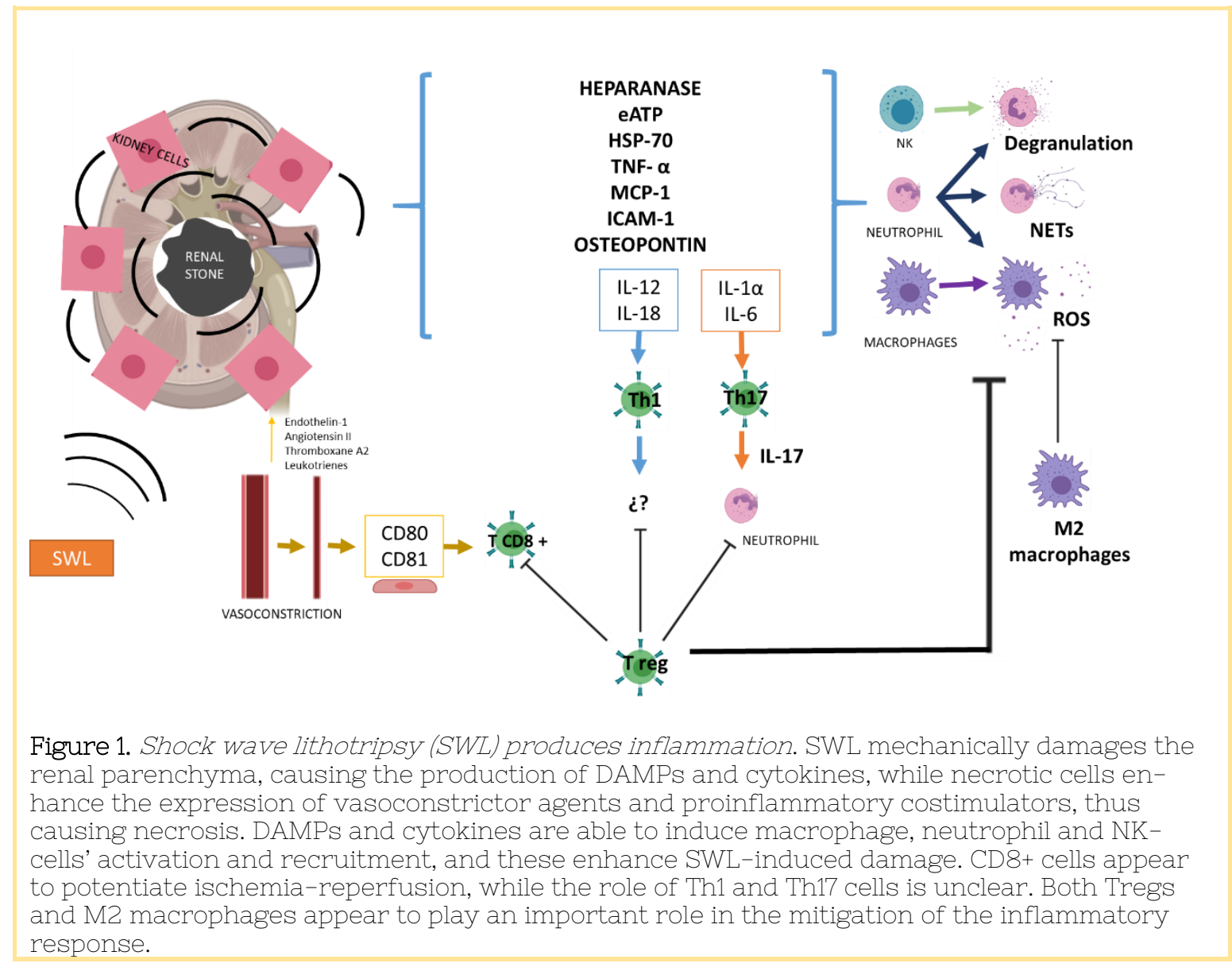


SÖC̊IIÉÉÁAD

ESPAÑOLA DEBENEFICENCIAAC P A C H U C A

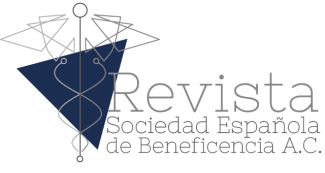

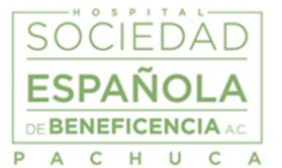

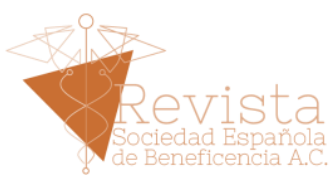

SOCIEDAD

ESPAÑOLA

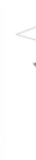

5. A putative model for heat-derived inflammation on intracorporeal laser lithotripsy

To our knowledge, there is no data regarding the topic of inflammation produced by heat-derived damage in the kidneys, so that, as for ILL-induced thermal injuries, we can only surmise a general pathophysiological mechanism based on information on other models of heat damage-derived inflammation.

Burnt tissues are not only obviously damaged, but are also prone to be infected, so that the recognition of pathogen-associated molecular patterns (PAMPs) and DAMPs is readily active, thus activating dendritic cells (DCs), monocytes and neutrophils to produce a vast array of both proinflammatory and antinflamatory cytokines as well as chemokines 116 that orchestrate the recruitment and activation of many leukocytes. Pro-inflammatory cytokines produced by such cells include TNF $\alpha$, IL-6, IL-12 and IL-1 $\beta$, while they also produce the anti-inflammatory cytokines IL-10 and TGF- $\beta^{117}$. Activated DCs, monocytes and macrophages locally process phagocytosed antigens for their display in major histocompatibility (MHC) class II molecules, to activate both an exacerbated Th17 and a late regulatory Th2immune response ${ }^{118}$.

Through the release of IL-17, Th-17 cells induce the recruitment and activation of neutrophils, with aims to control the propagation of microbes and clean necrotic debris as early as 3 hours post-burn ${ }^{119}$. In the first week, pro-inflammatoy cytokines such as TNFa, IL-6, IL-8, IL-1 $\boldsymbol{\beta}$ along with anti-inflammatory cytokines such as IL-10 are increased ${ }^{120}$, nonetheless, a predominant Th2-type arises later, as to orchestrate tissue scarring and healing ${ }^{118}$. While this is a good way to restrain damage progression in many tissues, enhanced fibrosis in the kidneys may lead to CKD.

\section{Conclusions}

Nephrolithiasis is an increasingly common disease that is very diverse in its clinical presentations, which compels the use of different clinical approaches. However, most kidney stones are treated with either SWL or ILL, both being effective and non-invasive therapies. Although these therapeutic approaches are considered to be relatively safe, they are prone to produce mechanical and thermal damage to the renal tissues, as well as ischemia, which further enhances damage through the induction of an interesting inflammatory response.

Much research about the roles of inflammatory mediators in such therapy is needed in order to understand its pathophysiological mechanisms. In that way, a pharmacological approach may be taken to limit the extent of damage induced by lithotripsy, and thus enhance the ability of this therapy to heal nephrolithiasis and avoid AKI. Also, the potential role of lithotripsy in the induction of CKD has 
SÖC̊IIÉÉÁAD

ESPAÑOLA BENEFICENCIA AC

P A C H U C A

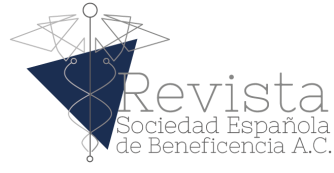

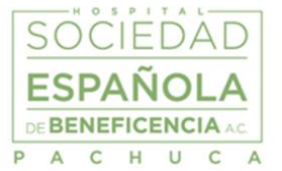

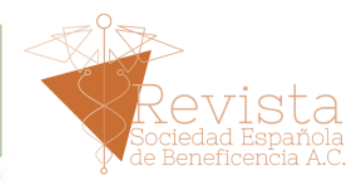

been neglected, in such a way that there are no studies regarding the long-term effects of such therapy, much less, studies that analyze the role of inflammation in the production of such pathology. It is a rather unlikely scenario, but it should not be ruled out, especially considering that very few studies show its implications in CKD production.

As to the question if lithotripsy is a friend or a foe, it is clearly a friend, as it has a proven efficacy in the management of nephrolithiasis. Nonetheless, the oxidative stress that arises as a consequence of such therapy has to be managed, and perhaps an effective way to do it is to control inflammation during the process. In regards to such an inflammatory response, it seems clear the intimate involvement of innate immunity, as neutrophils and macrophages appear to play an important role in damage induction. At the same time, Tregs also seem to play an important role in such cells-derived damage mitigation. These data render macrophages and neutrophils as plausible targets to dampen inflammation, whereas Treg-induction may be a central piece to such strategy.

\section{Acknowledgements}

All the authors wish to thank Sociedad Española de Beneficencia (Pachuca, Hidalgo) for funding the publication of this article. Moreover, Lucero A. TorresAlarcón, Mario F. Gómez-Núñez, Mariel Castillo-López and César D. SánchezHernández wish to thank the scholarship they receive from such Institution.

\section{Conflicts of interest}

None of the authors have any conflict of interest to declare.

\section{References}

1 Bellomo, R., Kellum, J. A. \& Ronco, C. Acute kidney injury. Lancet 380, 756-766, doi:10.1016/S0140-6736(11)61454-2 (2012).

2 Bellomo, R. et al. Acute renal failure - definition, outcome measures, animal models, fluid therapy and information technology needs: the Second International Consensus Conference of the Acute Dialysis Quality Initiative (ADQI) Group. Critical care 8, R204-212, doi:10.1186/cc2872 (2004).

3 Gomez, H. \& Kellum, J. A. Sepsis-induced acute kidney injury. Current opinion in critical care 22, 546-553, doi:10.1097/MCC.0000000000000356 (2016).

4 Mulay, S. R., Holderied, A., Kumar, S. V. \& Anders, H. J. Targeting Inflammation in So-Called Acute Kidney Injury. Seminars in nephrology 36, 17-30, doi:10.1016/j.semnephrol.2016.01.006 (2016).

5 Burmeister, D. M., Gomez, B. I. \& Dubick, M. A. Molecular mechanisms of trauma-induced acute kidney injury: Inflammatory and metabolic insights from animal models. Biochimica et 
biophysica acta. Molecular basis of disease 1863, 2661-2671, doi:10.1016/j.bbadis.2017.04.011 (2017).

6 Agarwal, A. et al. Cellular and Molecular Mechanisms of AKI. Journal of the American Society of Nephrology: JASN27, 12881299, doi:10.1681/ASN.2015070740 (2016).

7 Lamb, E. J., Levey, A. S. \& Stevens, P. E. The Kidney Disease Improving Global Outcomes (KDIGO) guideline update for chronic kidney disease: evolution not revolution. Clinical chemistry 59, 462465, doi:10.1373/clinchem.2012.184259 (2013).

$8 \quad$ Zhong, J., Yang, H. C. \& Fogo, A. B. A perspective on chronic kidney disease progression. American journal of physiology. Renal physiology 312, F375-F384, doi:10.1152/ajprenal.00266.2016 (2017).

$9 \quad$ Tuot, D. S. \& Plantinga, L. C. What patients don't know may hurt them: knowledge and the perception of knowledge among patients with CKD. Kidney international 80, 1256-1257, doi:10.1038/ki.2011.269 (2011).

10 Tuot, D. S. et al. Chronic kidney disease awareness among individuals with clinical markers of kidney dysfunction. Clinical journal of the American Society of Nephrology : CJASN 6, 18381844, doi:10.2215/CJN.00730111 (2011).

11 Ludwig, W. W. \& Matlaga, B. R. Urinary Stone Disease: Diagnosis, Medical Therapy, and Surgical Management. The Medical clinics of North America 102, 265-277, doi:10.1016/j.mcna.2017.10.004 (2018).

12 Sorokin, I. et al. Epidemiology of stone disease across the world. World journal of urology 35, 1301-1320, doi:10.1007/s00345-0172008-6 (2017).

13 Ziemba, J. B. \& Matlaga, B. R. Epidemiology and economics of nephrolithiasis. Investigative and clinical urology 58, 299-306, doi:10.4111/icu.2017.58.5.299 (2017).

14 Ferraro, P. M. et al. History of kidney stones and the risk of coronary heart disease. Jama 310, 408-415, doi:10.1001/jama.2013.8780 (2013).

15 Liu, Y. et al. Kidney stones and cardiovascular risk: a meta-analysis of cohort studies. American journal of kidney diseases : the official journal of the National Kidney Foundation 64, 402-410, doi:10.1053/j.ajkd.2014.03.017 (2014).

16 Domingos, F. \& Serra, A. Metabolic syndrome: a multifaceted risk factor for kidney stones. Scandinavian journal of urology 48, 414419, doi:10.3109/21681805.2014.903513 (2014).

17 Shavit, L. et al. Vascular calcification and bone mineral density in recurrent kidney stone formers. Clinical journal of the American Society of Nephrology: CJASN10, 278-285, doi:10.2215/CJN.06030614 (2015). 
18 Zisman, A. L., Evan, A. P., Coe, F. L. \& Worcester, E. M. Do kidney stone formers have a kidney disease? Kidney international 88, 1240-1249, doi:10.1038/ki.2015.254 (2015).

19 El-Zoghby, Z. M. et al. Urolithiasis and the risk of ESRD. Clinical journal of the American Society of Nephrology : CJASN7, 1409-1415, doi:10.2215/CJN.03210312 (2012).

20 Shrestha, A., Chhettri, P., Yadav, B. K., Basnet, R. B. \& Shrestha, P. M. Urinary Stone Disease and Preventable Nephrectomies. Journal of Nepal Health Research Council 17, 238-241, doi:10.33314/jnhrc.vOiO.1996 (2019).

21 Chung, J. M., Park, B. K., Kim, J. H., Lee, H. J. \& Lee, S. D. Impact of repeated extracorporeal shock wave lithotripsy on prepubertal rat kidney. Urolithiasis 46, 549-558, doi:10.1007/s00240-017-1011-0 (2018).

22 Clark, D. L. et al. Localization of renal oxidative stress and inflammatory response after lithotripsy. BJU international 103, 1562-1568, doi:10.1111/j.1464-410X.2008.08260.x (2009).

23 Evan, A. P., Willis, L. R., Lingeman, J. E. \& McAteer, J. A. Renal trauma and the risk of long-term complications in shock wave lithotripsy. Nephron 78, 1-8, doi:10.1159/000044874 (1998).

24 Dziegala, M., Krajewski, W., Kolodziej, A., Dembowski, J. \& Zdrojowy, R. Evaluation and physiopathology of minor transient shock wave lithotripsy - induced renal injury based on urinary biomarkers levels. Central European journal of urology71, 214-220, doi:10.5173/ceju.2018.1629 (2018).

25 Villanyi, K. K., Szekely, J. G., Farkas, L. M., Javor, E. \& Pusztai, C. Short-term changes in renal function after extracorporeal shock wave lithotripsy in children. The Journal of urology 166, 222-224, doi:10.1016/s0022-5347(05)66130-7 (2001).

26 Nasseh, H., Abdi, S., Roshani, A. \& Kazemnezhad, E. Urinary Beta2Microglobulin: An Indicator of Renal Tubular Damage after Extracorporeal Shock Wave Lithotripsy. Urology journal13, 29112915 (2016).

27 Jobs, K. et al. Interleukin-18 and NGAL in assessment of ESWL treatment safety in children with urolithiasis. Central-European journal of immunology 39, 384-391, doi:10.5114/ceji.2014.45952 (2014).

28 Liu, C. et al. The Efficacy of Percutaneous Nephrolithotomy Using Pneumatic Lithotripsy vs. the Holmium Laser: a Randomized Study. The Indian journal of surgery79, 294-298, doi:10.1007/s12262-0161473-2 (2017).

29 Aldoukhi, A. H. et al. Caliceal Fluid Temperature During High-Power Holmium Laser Lithotripsy in an In Vivo Porcine Model. Journal of endourology 32, 724-729, doi:10.1089/end.2018.0395 (2018). 
30 Barbas, C., Garcia, A., Saavedra, L. \& Muros, M. Urinary analysis of nephrolithiasis markers. J Chromatogr B Analyt Technol Biomed Life Sci781, 433-455 (2002).

31 Coe, F. L., Evan, A. \& Worcester, E. Kidney stone disease. J Clin Invest 115, 2598-2608, doi:10.1172/JCI26662 (2005).

32 Connor-Stroud, F. R. et al. Extensive vascular mineralization in the brain of a chimpanzee (Pan troglodytes). Comp Med 64, 224-229 (2014).

33 Hesse, A., Brandle, E., Wilbert, D., Kohrmann, K. U. \& Alken, P. Study on the prevalence and incidence of urolithiasis in Germany comparing the years 1979 vs. 2000. Eur Urol 44, 709-713, doi:10.1016/s0302-2838(03)00415-9 (2003).

$34 \mathrm{Kim}, \mathrm{S}$. C. et al. Cystine calculi: correlation of CT-visible structure, CT number, and stone morphology with fragmentation by shock wave lithotripsy. Urological research 35, 319-324, doi:10.1007/s00240-007-0117-1 (2007).

35 Preminger, G. M. et al. 2007 Guideline for the management of ureteral calculi. European urology 52, 1610-1631, doi:10.1016/j.eururo.2007.09.039 (2007).

36 Coll, D. M., Varanelli, M. J. \& Smith, R. C. Relationship of spontaneous passage of ureteral calculi to stone size and location as revealed by unenhanced helical CT. AJR. American journal of roentgenology 178, 101-103, doi:10.2214/ajr.178.1.1780101 (2002).

37 Trinchieri, A. Epidemiology of urolithiasis: an update. Clinical cases in mineral and bone metabolism : the official journal of the Italian Society of Osteoporosis, Mineral Metabolism, and Skeletal Diseases 5, 101-106 (2008).

38 Stamatelou, K. K., Francis, M. E., Jones, C. A., Nyberg, L. M. \& Curhan, G. C. Time trends in reported prevalence of kidney stones in the United States: 1976-1994. Kidney international 63, 1817-1823, doi:10.1046/j.1523-1755.2003.00917.x (2003).

39 Trinchieri, A. \& Moretti, R. Trends in prostate cancer epidemiology in the year 2000. Archivio italiano di urologia, andrologia : organo ufficiale [di] Societa italiana di ecografia urologica e nefrologica 77, 164-166 (2005).

40 Harris, H., Mittwoch, U., Robson, E. B. \& Warren, F. L. Phenotypes and genotypes in cystinuria. Annals of human genetics 20, 57-91, doi:10.1111/j.1469-1809.1955.tb01278.x (1955).

41 Lin, K. J. et al. The impact of climate factors on the prevalence of urolithiasis in Northern Taiwan. Biomedical journal 37, 24-30, doi:10.4103/2319-4170.117888 (2014).

42 Chaudhary, A., Singla, S. K. \& Tandon, C. In vitro Evaluation of Terminalia arjuna on Calcium Phosphate and Calcium Oxalate Crystallization. Indian J Pharm Sci 72, 340-345, doi:10.4103/0250474X.70480 (2010). 
SÖC̊İÉEAAD ESPAÑOLA BENEFICENCIA AC A C H U C A

43 Coe, F. L., Parks, J. H. \& Asplin, J. R. The pathogenesis and treatment of kidney stones. N Engl J Med 327, 1141-1152, doi:10.1056/NEJM199210153271607 (1992).

44 Dal Moro, F., Mancini, M., Tavolini, I. M., De Marco, V. \& Bassi, P. Cellular and molecular gateways to urolithiasis: a new insight. Urol Int 74, 193-197, doi:10.1159/000083547 (2005).

45 Griffith, D. P. Struvite stones. Kidney Int 13, 372-382, doi:10.1038/ki.1978.55 (1978).

46 Ngo, T. C. \& Assimos, D. G. Uric Acid nephrolithiasis: recent progress and future directions. Rev Urol 9, 17-27 (2007).

47 Ahmed, K., Dasgupta, P. \& Khan, M. S. Cystine calculi: challenging group of stones. Postgrad Med J82, 799-801, doi:10.1136/pgmj.2005.044156 (2006).

48 Schuler, T. D., Shahani, R., Honey, R. J. \& Pace, K. T. Medical expulsive therapy as an adjunct to improve shockwave lithotripsy outcomes: a systematic review and meta-analysis. Journal of endourology 23, 387-393, doi:10.1089/end.2008.0216 (2009).

49 Skolarikos, A. et al. The Efficacy of Medical Expulsive Therapy (MET) in Improving Stone-free Rate and Stone Expulsion Time, After Extracorporeal Shock Wave Lithotripsy (SWL) for Upper Urinary Stones: A Systematic Review and Meta-analysis. Urology 86, 10571064, doi:10.1016/j.urology.2015.09.004 (2015).

50 Bernardo, N. O. \& Smith, A. D. Chemolysis of urinary calculi. The Urologic clinics of North America 27, 355-365 (2000).

51 Preminger, G. M. et al. Chapter 1: AUA guideline on management of staghorn calculi: diagnosis and treatment recommendations. The Journal of urology 173, 1991-2000, doi:10.1097/01.ju.0000161171.67806.2a (2005).

52 Fernstrom, I. \& Johansson, B. Percutaneous pyelolithotomy. A new extraction technique. Scandinavian journal of urology and nephrology 10, 257-259, doi:10.1080/21681805.1976.11882084 (1976).

53 Manohar, T., Jain, P. \& Desai, M. Supine percutaneous nephrolithotomy: Effective approach to high-risk and morbidly obese patients. Journal of endourology 21, 44-49, doi:10.1089/end.2006.0212 (2007).

54 Schafer, A. I. Effects of nonsteroidal antiinflammatory drugs on platelet function and systemic hemostasis. Journal of clinical pharmacology 35, 209-219, doi:10.1002/j.1552-4604.1995.tb04050.x (1995).

55 Segura, J. W. et al. Ureteral Stones Clinical Guidelines Panel summary report on the management of ureteral calculi. The American Urological Association. The Journal of urology 158, $1915-$ 1921, doi:10.1016/s0022-5347(01)64173-9 (1997).

56 Mariotto, S. et al. Extracorporeal shock wave therapy in inflammatory diseases: molecular mechanism that triggers anti- 


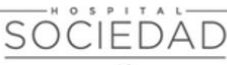

ESPAÑOLA

BENEFICENCIA AC

$P$ A C H U C A

inflammatory action. Current medicinal chemistry 16, 2366-2372, doi:10.2174/092986709788682119 (2009).

57 Torricelli, F. C. et al. Extracorporeal shock wave lithotripsy in the treatment of renal and ureteral stones. Revista da Associacao Medica Brasileira 61, 65-71, doi:10.1590/1806-9282.61.01.065 (2015).

58 Mustafa, M., Aburas, H., Helo, F. M. \& Qarawi, L. Electromagnetic and Electrohydraulic Shock Wave Lithotripsy-Induced Urothelial Damage: Is There a Difference? Journal of endourology 31, 180-184, doi:10.1089/end.2016.0644 (2017).

59 Kira, V. M. et al. Effects of repeated extracorporeal shock wave on kidney apoptosis of normal and diabetic rat. International brazj urol: official journal of the Brazilian Society of Urology 34, 91-96, doi:10.1590/s1677-55382008000100013 (2008).

60 Dhar, N. B., Thornton, J., Karafa, M. T. \& Streem, S. B. A multivariate analysis of risk factors associated with subcapsular hematoma formation following electromagnetic shock wave lithotripsy. The Journal of urology 172, 2271-2274, doi:10.1097/01.ju.0000143459.03836.2d (2004).

61 Jang, Y. B. et al. Treatment of subcapsular haematoma, a complication of extracorporeal shock wave lithotripsy (ESWL), by percutaneous drainage. Nephrology, dialysis, transplantation: official publication of the European Dialysis and Transplant Association - European Renal Association 21, 1117-1118, doi:10.1093/ndt/gfk002 (2006).

62 Smith, L. H. et al. National High Blood Pressure Education Program (NHBPEP) review paper on complications of shock wave lithotripsy for urinary calculi. The American journal of medicine 91, 635-641, doi:10.1016/0002-9343(91)90217-1 (1991).

63 Bianchi, G., Marega, D., Knez, R., Bucci, S. \& Trombetta, C. Comparison of an electromagnetic and an electrohydraulic lithotripter: Efficacy, pain and complications. Archivio italiano di urologia, andrologia : organo ufficiale [di] Societa italiana di ecografia urologica e nefrologica 90, 169-171, doi:10.4081/aiua.2018.3.169 (2018).

64 Lambert, E. H., Walsh, R., Moreno, M. W. \& Gupta, M. Effect of escalating versus fixed voltage treatment on stone comminution and renal injury during extracorporeal shock wave lithotripsy: a prospective randomized trial. The Journal of urology 183, 580-584, doi:10.1016/j.juro.2009.10.025 (2010).

65 Li, K. et al. Optimal frequency of shock wave lithotripsy in urolithiasis treatment: a systematic review and meta-analysis of randomized controlled trials. The Journal of urology 190, 1260-1267, doi:10.1016/j.juro.2013.03.075 (2013).

66 Chacko, J., Moore, M., Sankey, N. \& Chandhoke, P. S. Does a slower treatment rate impact the efficacy of extracorporeal shock wave 
SÖC̊IIÉÉÁtD

ESPAÑOLA

BENEFICENCIA $A C$

$P$ A C H U C A

lithotripsy for solitary kidney or ureteral stones? The Journal of urology 175, 1370-1373; discussion 1373-1374, doi:10.1016/S00225347(05)00683-X (2006).

67 D'Addessi, A. et al. Complications of extracorporeal shock wave lithotripsy for urinary stones: to know and to manage them-a review. TheScientificWorldJournal2012, 619820, doi:10.1100/2012/619820 (2012).

68 Clark, D. L., Connors, B. A., Handa, R. K. \& Evan, A. P. Pretreatment with low-energy shock waves reduces the renal oxidative stress and inflammation caused by high-energy shock wave lithotripsy. Urological research 39, 437-442, doi:10.1007/s00240-011-0372-z (2011).

69 Yamashita, S. et al. Variation Coefficient of Stone Density: A Novel Predictor of the Outcome of Extracorporeal Shockwave Lithotripsy. Journal of endourology 31, 384-390, doi:10.1089/end.2016.0719 (2017).

70 Aldoukhi, A. H., Black, K. M. \& Ghani, K. R. Emerging Laser Techniques for the Management of Stones. The Urologic clinics of North America 46, 193-205, doi:10.1016/j.ucl.2018.12.005 (2019).

71 Black, K. M., Aldoukhi, A. H. \& Ghani, K. R. A Users Guide to Holmium Laser Lithotripsy Settings in the Modern Era. Frontiers in surgery 6, 48, doi:10.3389/fsurg.2019.00048 (2019).

72 Sea, J. et al. Optimal power settings for Holmium:YAG lithotripsy. The Journal of urology 187, 914-919, doi:10.1016/j.juro.2011.10.147 (2012).

73 Aldoukhi, A. H., Roberts, W. W., Hall, T. L. \& Ghani, K. R. Holmium Laser Lithotripsy in the New Stone Age: Dust or Bust? Frontiers in surgery 4, 57, doi:10.3389/fsurg.2017.00057 (2017).

74 Matlaga, B. R. et al. Ureteroscopic Laser Lithotripsy: A Review of Dusting vs Fragmentation with Extraction. Journal of endourology 32, 1-6, doi:10.1089/end.2017.0641 (2018).

75 Humphreys, M. R. et al. Dusting versus Basketing during Ureteroscopy-Which Technique is More Efficacious? A Prospective Multicenter Trial from the EDGE Research Consortium. The Journal of urology 199, 1272-1276, doi:10.1016/j.juro.2017.11.126 (2018).

76 Dauw, C. A. et al. Contemporary Practice Patterns of Flexible Ureteroscopy for Treating Renal Stones: Results of a Worldwide Survey. Journal of endourology 29, 1221-1230, doi:10.1089/end.2015.0260 (2015).

77 Winship, B. et al. Holmium:YAG Laser Pulse Type Affects Irrigation Temperatures in a Benchtop Ureteral Model. Journal of endourology, doi:10.1089/end.2019.0496 (2019).

78 Hein, S., Petzold, R., Schoenthaler, M., Wetterauer, U. \& Miernik, A. Thermal effects of Ho: YAG laser lithotripsy: real-time evaluation in an in vitro model. World journal of urology 36, 1469-1475, doi:10.1007/s00345-018-2303-x (2018). 
SÖC̊IIÉÉÁtD

ESPAÑOLA

BENEFICENCIA AC

A $C$ C

79 Auge, B. K. et al. Ureteral access sheath provides protection against elevated renal pressures during routine flexible ureteroscopic stone manipulation. Journal of endourology 18, 33-36, doi:10.1089/089277904322836631 (2004).

80 Jung, H., Norby, B., Frimodt-Moller, P. C. \& Osther, P. J. Endoluminal isoproterenol irrigation decreases renal pelvic pressure during flexible ureterorenoscopy: a clinical randomized, controlled study. European urology 54, 1404-1413, doi:10.1016/j.eururo.2008.03.092 (2008).

81 Rehman, J. et al. Characterization of intrapelvic pressure during ureteropyeloscopy with ureteral access sheaths. Urology 61, 713718, doi:10.1016/s0090-4295(02)02440-8 (2003).

82 Mehta, R. L. et al. Acute Kidney Injury Network: report of an initiative to improve outcomes in acute kidney injury. Critical care 11, R31, doi:10.1186/cc5713 (2007).

83 Bonventre, J. V. \& Yang, L. Cellular pathophysiology of ischemic acute kidney injury. The Journal of clinical investigation 121, 42104221, doi:10.1172/JCI45161 (2011).

84 Zhang, J. J. et al. Numerical Response Surfaces of Volume of Ablation and Retropulsion Amplitude by Settings of Ho:YAG Laser Lithotripter. Journal of healthcare engineering 2018, 8261801, doi:10.1155/2018/8261801 (2018).

85 Kroczak, T. et al. Dual usage of a stone basket: Stone capture and retropulsion prevention. Canadian Urological Association journal = Journal de l'Association des urolog'ues du Canada 12, 280-283, doi:10.5489/cuaj.5021 (2018).

86 Clark, D. L., Connors, B. A., Evan, A. P., Handa, R. K. \& Gao, S. Effect of shock wave number on renal oxidative stress and inflammation. BJU international 107, 318-322, doi:10.1111/j.1464-410X.2010.09311.x (2011).

87 Bas, M. et al. Curcumin prevents shock-wave lithotripsy-induced renal injury through inhibition of nuclear factor kappa-B and inducible nitric oxide synthase activity in rats. Urological research 37, 159-164, doi:10.1007/s00240-009-0186-4 (2009).

88 Goktas, C. et al. Evaluating ESWL-induced renal injury based on urinary TNF-alpha, IL-1alpha, and IL-6 levels. Urological research 40, 569-573, doi:10.1007/s00240-012-0467-1 (2012).

89 Rhee, E., Santiago, L., Park, E., Lad, P. \& Bellman, G. C. Urinary IL-6 is elevated in patients with urolithiasis. The Journal of urology 160, 2284-2288, doi:10.1097/00005392-199812010-00101 (1998).

90 Conger, J. Hemodynamic factors in acute renal failure. Advances in renal replacement therapy 4, 25-37 (1997).

91 Karlberg, L., Norlen, B. J., Ojteg, G. \& Wolgast, M. Impaired medullary circulation in postischemic acute renal failure. Acta physiologica Scandinavica 118, 11-17, doi:10.1111/j.1748-1716.1983.tb07234.x (1983). 
SÖC̊İÉEAAD ESPAÑOLA DEBNEFICENCIA AC

92 Kelly, K. J. et al. Intercellular adhesion molecule-1-deficient mice are protected against ischemic renal injury. The Journal of clinical investigation 97, 1056-1063, doi:10.1172/JC1118498 (1996).

93 Bonventre, J. V. \& Zuk, A. Ischemic acute renal failure: an inflammatory disease? Kidney international 66, 480-485, doi:10.1111/j.1523-1755.2004.761_2.x (2004).

94 Wahl, P. et al. Renal tubular epithelial expression of the costimulatory molecule B7RP-1 (inducible costimulator ligand). Journal of the American Society of Nephrology: JASN13, 1517-1526, doi:10.1097/01.asn.0000017901.77985f (2002).

95 Niemann-Masanek, U., Mueller, A., Yard, B. A., Waldherr, R. \& van der Woude, F. J. B7-1 (CD80) and B7-2 (CD 86) expression in human tubular epithelial cells in vivo and in vitro. Nephron 92, 542-556, doi:10.1159/000064084 (2002).

96 Burne, M. J. et al. Identification of the CD4(+) T cell as a major pathogenic factor in ischemic acute renal failure. The Journal of clinical investigation 108, 1283-1290, doi:10.1172/JC112080 (2001).

97 Nakazawa, D. et al. Histones and Neutrophil Extracellular Traps Enhance Tubular Necrosis and Remote Organ Injury in Ischemic AKI. Journal of the American Society of Nephrology : JASN28, 17531768, doi:10.1681/A.SN.2016080925 (2017).

98 Farag, M. M., Khalifa, A. A., Elhadidy, W. F. \& Rashad, R. M. Hepatorenal protection in renal ischemia/reperfusion by celecoxib and pentoxifylline. The Journal of surgical research 204, 183-191, doi:10.1016/j.jss.2016.04.064 (2016).

99 Wang, C. et al. Rutaecarpine alleviates renal ischemia reperfusion injury in rats by suppressing the JNK/p38 MAPK signaling pathway and interfering with the oxidative stress response. Molecular medicine reports 16, 922-928, doi:10.3892/mmr.2017.6631 (2017).

100 Jansen, M. P. et al. Release of extracellular DNA influences renal ischemia reperfusion injury by platelet activation and formation of neutrophil extracellular traps. Kidney international 91, 352-364, doi:10.1016/j.kint.2016.08.006 (2017).

101 Cen, C. et al. Osteopontin Blockade Attenuates Renal Injury After Ischemia Reperfusion by Inhibiting NK Cell Infiltration. Shock 47, 52-60, doi:10.1097/shk.0000000000000721 (2017).

102 Li, L. et al. The chemokine receptors CCR2 and CX3CR1 mediate monocyte/macrophage trafficking in kidney ischemia-reperfusion injury. Kidney international74, 1526-1537, doi:10.1038/ki.2008.500 (2008).

103 Koo, T. Y. et al. The P2X7 receptor antagonist, oxidized adenosine triphosphate, ameliorates renal ischemia-reperfusion injury by expansion of regulatory T cells. Kidney international 92, 415-431, doi:10.1016/j.kint.2017.01.031 (2017). 


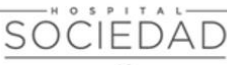

ESPAÑOLA BENEFICENCIAAC

P A $C$ C

104 Masola, V. et al. Heparanase regulates the M1 polarization of renal macrophages and their crosstalk with renal epithelial tubular cells after ischemia/reperfusion injury. FASEB journal : official publication of the Federation of American Societies for Experimental Biology 32, 742-756, doi:10.1096/fj.201700597R (2018).

105 Wang, Q. et al. Atorvastatin alleviates renal ischemia-reperfusion injury in rats by promoting M1-M2 transition. Molecular medicine reports 15, 798-804, doi:10.3892/mmr.2016.6074 (2017).

106 Jeong, E. K. et al. Protective effect of eupatilin against renal ischemia-reperfusion injury in mice. Transplantation proceeding's 47, 757-762, doi:10.1016/j.transproceed.2014.12.044 (2015).

107 Ascon, M. et al. Renal ischemia-reperfusion leads to long term infiltration of activated and effector-memory T lymphocytes. Kidney international75, 526-535, doi:10.1038/ki.2008.602 (2009).

108 Lee, J. W. et al. Transcriptional modulation of the Thelper 17/interleukin 17 axis ameliorates renal ischemia-reperfusion injury. Nephrology, dialysis, transplantation: official publication of the European Dialysis and Transplant Association - European Renal Association 34, 1481-1498, doi:10.1093/ndt/gfy370 (2019).

109 Mehrotra, P. et al. IL-17 mediates neutrophil infiltration and renal fibrosis following recovery from ischemia reperfusion: compensatory role of natural killer cells in athymic rats. American journal of physiology. Renal physiology 312, F385-F397, doi:10.1152/ajprenal.00462.2016 (2017).

110 Xue, C. et al. Powerful protection against renal ischemia reperfusion injury by T cell-specific NF-kappaB inhibition. Transplantation 97, 391-396, doi:10.1097/01.tp.0000438622.89310.95 (2014).

111 Guo, L. et al. Lymphocyte-specific deletion of IKK2 or NEMO mediates an increase in intrarenal Th17 cells and accelerates renal damage in an ischemia-reperfusion injury mouse model. American journal of physiology. Renal physiology 311, F1005-f1014, doi:10.1152/ajprenal.00242.2016 (2016).

112 Yano, T. et al. The pathological role of IL-18Ralpha in renal ischemia/reperfusion injury. Laboratory investigation; a journal of technical methods and patholog'y 95, 78-91, doi:10.1038/labinvest.2014.120 (2015).

113 Bai, M. et al. IL-17A improves the efficacy of mesenchymal stem cells in ischemic-reperfusion renal injury by increasing Treg percentages by the COX-2/PGE2 pathway. Kidney international 93, 814-825, doi:10.1016/j.kint.2017.08.030 (2018).

114 Jun, C. et al. Protective effect of CD4(+)CD25(high)CD127(low) regulatory T cells in renal ischemia-reperfusion injury. Cellular immunology 289, 106-111, doi:10.1016/j.cellimm.2014.04.002 (2014). 


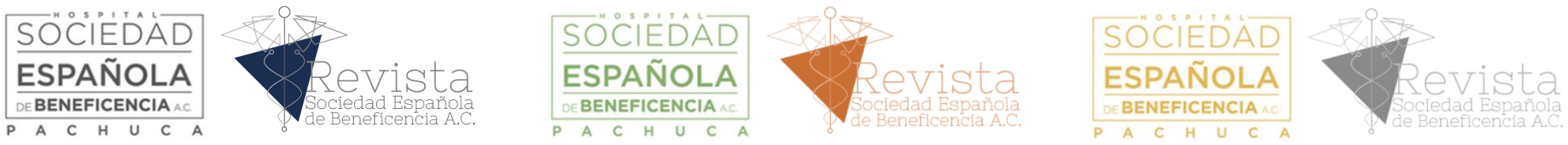

115 Jun, C. et al. Protective Effect of CXCR3(+)CD4(+)CD25(+)Foxp3(+) Regulatory T Cells in Renal Ischemia-Reperfusion Injury. Mediators of inflammation 2015, 360973, doi:10.1155/2015/360973 (2015).

116 Galbraith, N., Walker, S., Galandiuk, S., Gardner, S. \& Polk, H. C., Jr. The Significance and Challenges of Monocyte Impairment: For the Ill Patient and the Surgeon. Surgical infections 17, 303-312, doi:10.1089/sur.2015.245 (2016).

117 Galbraith, N., Walker, S., Carter, J. \& Polk, H. C., Jr. Past, Present, and Future of Augmentation of Monocyte Function in the Surgical Patient. Surgical infections 17, 563-569, doi:10.1089/sur.2016.014 (2016).

118 O'Sullivan, S. T. et al. Major injury leads to predominance of the T helper-2 lymphocyte phenotype and diminished interleukin-12 production associated with decreased resistance to infection. Annals of surgery 222, 482-490; discussion 490-482, doi:10.1097/00000658-199522240-00006 (1995).

119 Rendon, J. L. \& Choudhry, M. A. Th17 cells: critical mediators of host responses to burn injury and sepsis. Journal of leukocyte biology 92, 529-538, doi:10.1189/j1b.0212083 (2012).

120 Finnerty, C. C. et al. Temporal cytokine profiles in severely burned patients: a comparison of adults and children. Molecular medicine 14, 553-560, doi:10.2119/2007-00132.Finnerty (2008). 